

Original Research Article

https://doi.org/10.20546/ijcmas.2020.902.032

\title{
Assessment of Genetic Divergence for Quantitative Traits in Lens culinaris Medik
}

\author{
Soumya Satpathy* and Sandip Debnath \\ Department of Genetics and Plant Breeding, Institute of Agriculture, Visva-Bharati, \\ Sriniketan, Birbhum, West Bengal- 731236 (India) \\ *Corresponding author
}

Keywords

Lentil, Genetic divergence,

Mahalanobis's $\mathrm{D}^{2}$, Cluster analysis, Quantitative traits

\section{Article Info}

\section{Accepted:}

05 January 2019

Available Online:

10 February 2020

\section{A B S T R A C T}

Fifty genotypes of lentil were evaluated under normal soil condition in the field of Institute of Agriculture, Visva-Bharati University to assess genetic divergence using Mahalanobis's $\mathrm{D}^{2}$ analysis. The genotypes which were being developed at different crop improvement research centers across India and Bangladesh were collected for present investigation. Experiment was carried out over two crop seasons of 2017-18 and 2018-19 in Randomized Block Design with three replicates. Fifteen different clusters were formed as a result of pooled data analysis. Cluster I consisted largest number of genotypes. Twelve clusters had only single genotype in each of them. Maximum inter cluster distances was found between cluster II and cluster IV with eleven genotypes and one genotype in each, respectively. Cluster XIV having genotype ILL-10461 had shown maximum mean value for yield. Geographical and genetic diversity did not coincide while clustering.

\section{Introduction}

Lentil (Lens culinaris Medik.) is locally known as Masoor in India, Bangladesh, Nepal, Sri Lanka and Pakistan, Adas in Arabic, Mercimek in Turkey, Messer in Africa and Ethiopia and Heramame in Japan. It is a winter season crop grown predominantly in Asian subcontinent that accounts for $80 \%$ global area and 95\% production (Malik, 2005). Lens is a genus that belongs to family Fabaceae with six other annual recognized species such as $L$. culinaris ssp. odemensis, $L$. culinaris ssp.orientalis, $L$. ervoides, $L$. nigricans, $L$. lamottei and $L$. tomentosus. L. culinaris ssp.orientalis which is fully cross compatible with domesticated lentil is also considered as the putative ancestor. Cultivated lentil (Lens culinaris Medikus subsp. culinaris) is an annual crop, diploid $(2 n=14)$ in nature, self pollinated crop having lens shaped grains. Its estimated 
genome size is $4063 \mathrm{Mbp} / \mathrm{C}$ (Arumuganathan and Earle, 1991). It is a suitable crop for dry tracts that grows well in low water regime.

It is a rich source of protein in diet ranges from $22 \%$ to $34.6 \%$ (Callaway, 2004). Being a legume and also known as 'pulses' after cooking, it is a chief source of protein in diet and is an integral part of daily diet because of good amino acid balance.

Globally, lentil ranks sixth in terms of production among the major pulses after dry bean, pea, chickpea, faba bean and cowpea. It shows only $5-6 \%$ of the total area under pulses. In India, an area of 15 lakh ha (7.8\%) produces about 9.5 lakh tones $(7.7 \%)$ with a productivity of $633.3 \mathrm{~kg} / \mathrm{ha}$ of lentil among other pulses (Anonymous, 2018-19). West Bengal is reported to have $4 \%$ area under lentil with a production of $4.21 \%$ against an area of $40.53 \%$ in Madhya Pradesh and $45.79 \%$ production in Uttar Pradesh (Anonymous, 2018-19).

Some major constraints behind the low productivity of lentil in India are lack of suitable varieties, poor crop stand, diseases and insect pests, crop-weed competition due to short stature, poor Rhizobium and microbial activity, lack of care and attention as compared to cereals and oil seeds and non availability of good quality seeds.

Lentil is one of the oldest legumes known to man. Its cultivation dates back to $11,000 \mathrm{BC}$. However, it is an under exploited crop and there is tremendous scope for its genetic improvement. Inherent variability for different quantitative characters in the base material is essential for crop improvement programmes. Information on the nature and magnitude of genetic divergence in the population helps in choosing the diverse parents for meaningful crossing strategies (Gautam et al., 2013).
Genetic divergence is the process in which two or more populations of an ancestral species accumulate independent genetic changes (mutations) through time, often after the populations have become reproductively isolated for some period of time. It serves as a way for populations to adapt to changing environments. It can be measured through Metroglyph Analysis (Anderson, 1957) or $\mathrm{D}^{2}$ Analysis (Mahalanobis, 1936). Genetic divergence will always accompany reproductive isolation, either due to novel adaptations via selection and/or due to genetic drift, and is the principal mechanism underlying speciation

\section{Materials and Methods}

The present investigation was carried out in Agriculture farm of Institute of Agriculture, Visva-Bharati University, West Bengal, India. Fifty genotypes which were developed at various crop research stations across India and Bangladesh formed the experimental materials upon which data was recorded. The genotypes were Moitree, Pusa Ageti, Asha, Ranjan, Subrata, WBL-77-108, NDL-01, BLL-66, L-46-05, LL-147, L-14-16-01, L-9403, LEN-13-13, LIEN-07-E-32, LIEN-07-E11, E-28, F-23,LIF-03, LIF-03-03, LIF-03-1107, ILL-10461, ILL-10-971, ILL-10893, ILL8108, IC-05-03, IC-04-07, BLC-18, BLC-60, BLC-138, BLC-97, BLC-139,BLC-127, BLC-103, BLC-16, BLC-180, BLC-08, BLC98, BLC-58, BLC-32, BLC-88, BLC-173, BLC-126, BLC-01, BLC-25, BLC-90, BM1,BM-4, BM-5, BM-6, and BM-7 . Out of these, Asha, Ranjan, Subrata, Moitree and WBL-77 is being developed in West Bengal, India. Accessions with names starting from 'BM' have been developed in Bangladesh Agricultural Research Institute (Thus, known as BARI MASOOR), with 'IC' as initial have been developed at ICARDA, 'ILL' are international accessions and others with initials BLC, L and LL are developed in different agroclimatic zones of India at 
research stations of IIPR (Kanpur), JNKVV (Madhya Pradesh), IARI (New Delhi) and Almora. The above mentioned genotypes were subjected to test with three replicated trials over two winter seasons of 2017-18 and 2018-19 in Randomized Block Design (RBD). Data on sixteen quantitative character viz. days to $50 \%$ flowering, days to pod initiation, days to $50 \%$ pod maturity, plant height $(\mathrm{cm})$, primary branches per plant, secondary branches per plant, total branches per plant, root length $(\mathrm{cm})$, nodules per plant, pods per plant, seeds per pod, seeds per plant, biomass (g), 100 seed weight (g), harvest index $(\%)$ and grain yield/plant (g) were observed and recorded from five randomly chosen competitive plants. Pooled data over two years were subjected to analysis using software Windostat Version 9.2, licensed to Department of Genetics and Plant Breeding, Palli Siksha Bhavana, Visva-Bharati.

\section{Results and Discussion}

The analysis of variance indicated the existence of significant differences among the genotypes for all the characters under study implied there was presence of adequate genetic variability in the experimental material. Use of ' $\mathrm{V}$ ' statistic which, in turn, utilized Wilk's Criteria indicated significant differences between mean values of correlated variables. Thereby, analysis of genetic divergence among the tested lentil germplasm was considered to be relevant. A total of fifteen clusters were formed from fifty genotypes by Tocher method that consist genotypes as presented in table 1. Fig. 1 shows clustering by Tocher method. Cluster I was found to be the largest comprising nineteen genotypes followed by Cluster II, that consisted eleven genotypes and cluster III with eight genotypes. Cluster IV to XV were solitary and had one genotype each.

Inter and intra cluster distance has been presented in table 2. Inter cluster distances was highest between cluster II and cluster IV (29.38). The lowest inter cluster distance was found in cluster VII and cluster IX (1.92). The results implied that the inter cluster distances were mostly greater than intra cluster distance, which in turn suggested wider diversity among the germplasm of different groups. In other words, it can be said that the genotypes grouped together were less divergent than the ones that fall into different clusters. Thus, it will be logical to choose parents between clusters having largest inter cluster distance i.e. cluster II and IV for hybridization to obtain maximum heterosis. The intra cluster distances varied from 2.68 in cluster II to 4.00 in cluster III. Clusters IV, V, VI, VII, VIII, IX, X, XI, XII, XIII, XIV and $\mathrm{XV}$ had single genotype in each cluster with no intra cluster distance. This indicated that genotypes that were part of cluster II, in which intra cluster distance had lower value, were closely related among themselves in contrast to the genotypes fallen in cluster III. Intra and inter cluster distance aided in decision regarding the clusters from which parents were to be chosen for crossing.

The genotypes collected from diverse ecogeographical regions were distributed into different clusters randomly (Jeena and Singh, 2002). Grouping of genotypes of similar origin into different clusters indicated lack of any relationship between geographical and genetic diversity. This tendency of genotypes to occur in clusters cutting across geographical boundaries demonstrates that geographical isolation is not the only factor causing genetic diversity (Sihag et al., 2004). This also suggests that the genotypes within cluster may have some degree of ancestral relationship. Similar results were also earlier reported by Kumar et al., 2004 and Sirohi et al., 2007. The genetic divergence is an outcome of several factors such as changing of breeding material, genetic drift, natural variation and artificial selection other than ecological and geographical diversification 
(Sirohi et al., 2009). Thus, selection of parents for desirable cross combinations should be based on genetic diversity instead of geographic diversity to get superior recombinants and desirable segregants. However, caution should be taken while selecting divergent genotypes because such crosses may not yield proportionate heterosis response (Subhash chandra et al., 2009). Therefore, it is important to initiate a crossing programme by involving the genotypes belonging to different clusters with high means for almost all component traits. Moreover, the chosen divergent parents should have better combining ability to give rise to better cross combinations.

Fig. 2 shows Mahalanobis's Euclidean distance within and between clusters. Table 3 presents the values of cluster means.

Table.1 Grouping of Fifty Genotypes into Different Clusters

\begin{tabular}{|c|c|c|}
\hline Cluster & Number of Genotypes & Name of Genotypes \\
\hline $\mathbf{I}$ & 19 & $\begin{array}{l}\text { BLL-66 ,BLC-103, PUSA AGETI, } \\
\text { BLC88, LIF-03-11-07, IC-05-03, } \\
\text { BLC-58, L-94-03,L-46-05, BLC-98, } \\
\text { ASHA, LIF-03-03, BLC139, BLC- } \\
\text { 01, L-14-16-01, BLC-180, NDL-01, } \\
\text { BLC-138, ILL-8108 }\end{array}$ \\
\hline II & 11 & $\begin{array}{l}\text { LIEN-07-E-32,WBL-77-108, LIF-03, } \\
\text { RANJAN, BLC-90, MOITREE, } \\
\text { SUBRATA, BLC-16, BM-4, } \\
\text { F-23, BLC126 }\end{array}$ \\
\hline III & 8 & $\begin{array}{c}\text { E-28 ,BLC-127,LL-147,BLC-08,IC-04-07, } \\
\text { BLC-173,BLC-18,BLC-25 }\end{array}$ \\
\hline IV & 1 & BLC-60 \\
\hline V & 1 & BM-6 \\
\hline VI & 1 & LIEN-07-E-11 \\
\hline VII & 1 & BM-1 \\
\hline VIII & 1 & ILL-10-971 \\
\hline IX & 1 & ILL-10893 \\
\hline $\mathbf{X}$ & 1 & BLC-32 \\
\hline XI & 1 & BM-5 \\
\hline XII & 1 & BLC-97 \\
\hline XIII & 1 & BM-7 \\
\hline XIV & 1 & ILL-10461 \\
\hline $\mathbf{X V}$ & 1 & LEN-13-13 \\
\hline
\end{tabular}


Table.2 Average Intra and Inter Cluster Distances

\begin{tabular}{|c|c|c|c|c|c|c|c|c|c|c|c|c|c|c|c|}
\hline 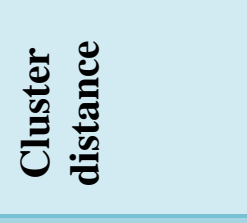 & 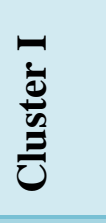 & 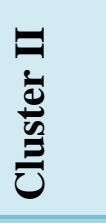 & $\begin{array}{l}\Xi \\
\vdots \\
\frac{\Xi}{0} \\
\frac{\Xi}{\Xi}\end{array}$ & $\frac{Z}{\vdots}$ & $\frac{7}{\vdots}$ & 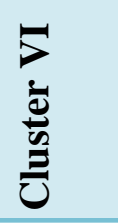 & 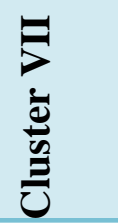 & $\begin{array}{l}\Xi \\
\nabla \\
\frac{0}{0} \\
\frac{0}{2}\end{array}$ &  & 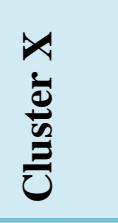 & 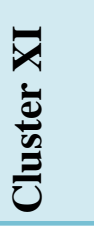 & 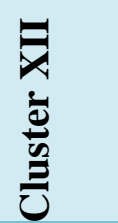 & $\begin{array}{l}\Xi \\
\bar{X} \\
\frac{\bar{\theta}}{0} \\
\frac{0}{\partial}\end{array}$ & 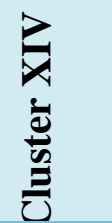 & 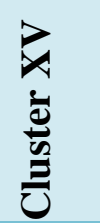 \\
\hline Cluster I & 2.75 & 8.29 & 5.24 & 11.9 & 3.58 & 3.62 & 6.22 & 3.67 & 4.49 & 4.72 & 3.75 & 5.44 & 5.15 & 5.07 & 5.42 \\
\hline Cluster II & & 2.68 & 17.69 & 29.38 & 7.61 & 6.03 & 5.21 & 8.12 & 7.15 & 7.11 & 9.3 & 15.87 & 5.33 & 11.84 & 10.88 \\
\hline Cluster III & & & 4 & 6.98 & 6.86 & 8 & 12.05 & 7 & 9.62 & 9.6 & 6.42 & 5.96 & 10.18 & 6.02 & 8.65 \\
\hline Cluster IV & & & & 0 & 13.93 & 16.16 & 22.86 & 12.91 & 17.58 & 13.94 & 11.9 & 10.01 & 20.29 & 8.84 & 15.22 \\
\hline Cluster V & & & & & 0 & 3.19 & 7.01 & 4.92 & 4.99 & 5.51 & 4.62 & 5.11 & 3.19 & 4.63 & 5.35 \\
\hline Cluster VI & & & & & & 0 & 6.82 & 5.1 & 6.87 & 5.85 & 6.68 & 8.92 & 4.84 & 7.84 & 7.89 \\
\hline Cluster VII & & & & & & & 0 & 5.91 & 7.3 & 7.43 & 6.47 & 13.45 & 4.55 & 7.19 & 11.1 \\
\hline Cluster VIII & & & & & & & & 0 & 1.92 & 6.93 & 2.55 & 7.18 & 5.59 & 4.75 & 6.75 \\
\hline Cluster IX & & & & & & & & & 0 & 6.53 & 3.49 & 6.08 & 6.58 & 6.75 & 5.67 \\
\hline Cluster X & & & & & & & & & & 0 & 5.77 & 5.87 & 5.91 & 7.14 & 4.29 \\
\hline Cluster XI & & & & & & & & & & & 0 & 5.16 & 5.64 & 3.92 & 6.11 \\
\hline Cluster XII & & & & & & & & & & & & 0 & 10.43 & 7.16 & 3.54 \\
\hline Cluster XIII & & & & & & & & & & & & & 0 & 6.32 & 6.99 \\
\hline Cluster XIV & & & & & & & & & & & & & & 0 & 7.01 \\
\hline Cluster XV & & & & & & & & & & & & & & & 0 \\
\hline
\end{tabular}


Figure.2 Mahalanobis's Euclidean Distance Within and Between Clusters

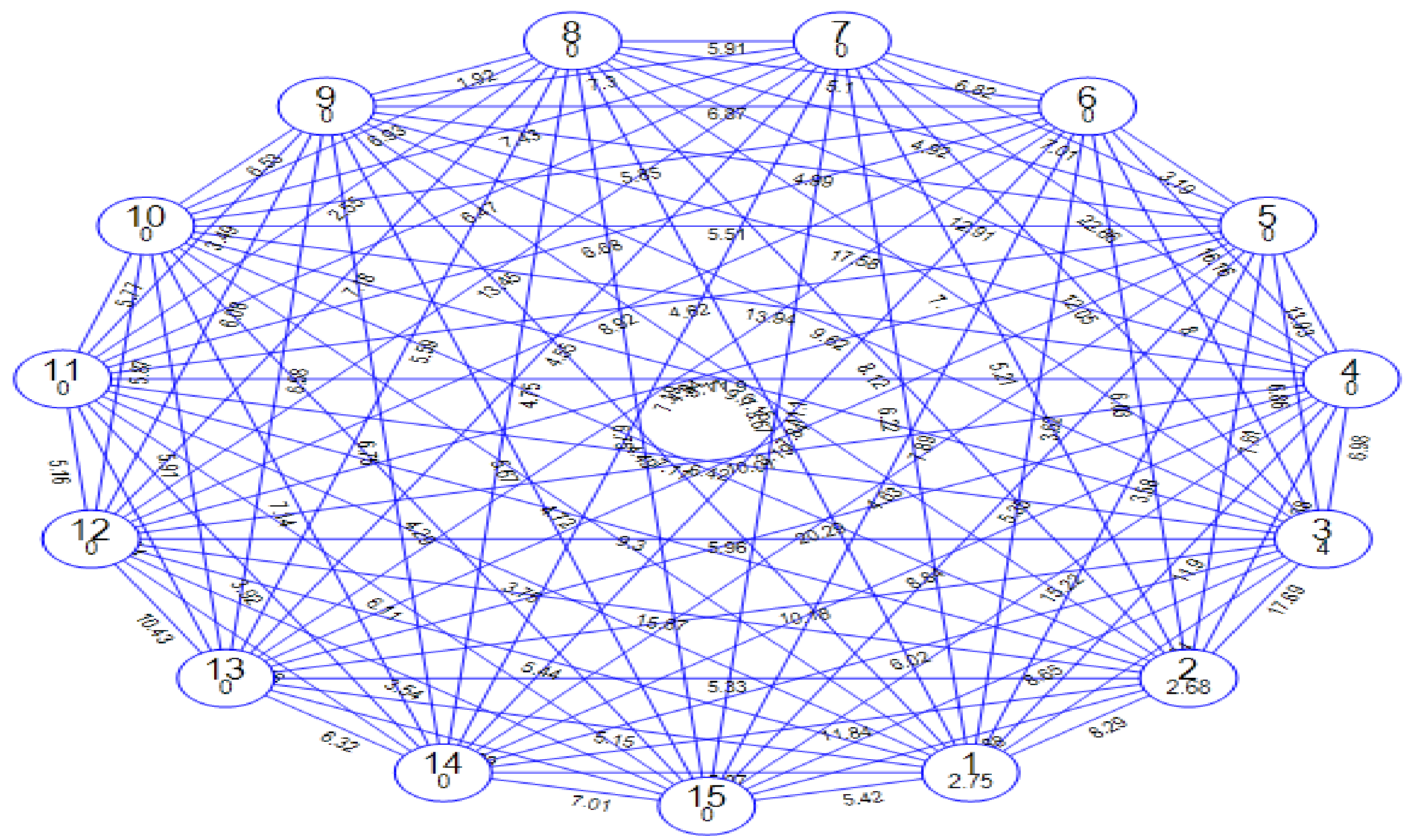


Table.3 Cluster Means for Different Characters under Study

\begin{tabular}{|c|c|c|c|c|c|c|c|c|c|c|c|c|c|c|c|c|}
\hline & 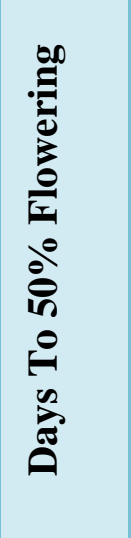 & 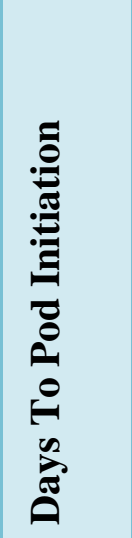 &  & 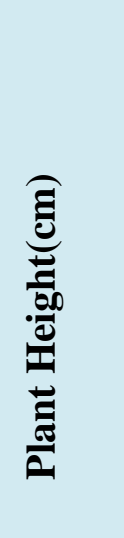 & 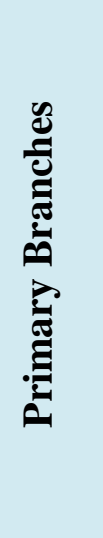 & 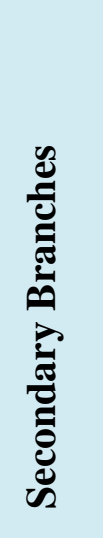 & 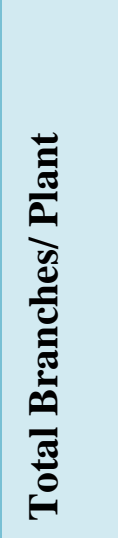 & 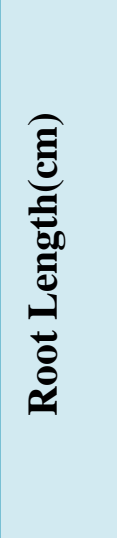 & 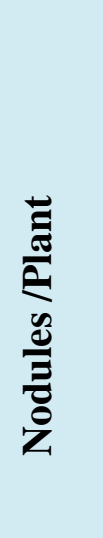 & $\frac{\vec{E}}{\stackrel{\vec{E}}{\tilde{E}}}$ & 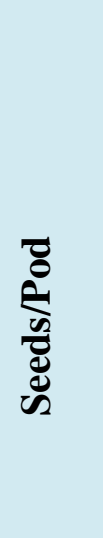 & 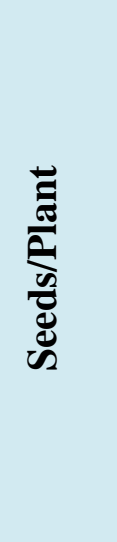 & 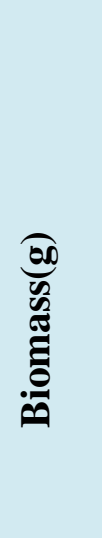 & 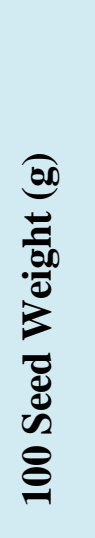 & 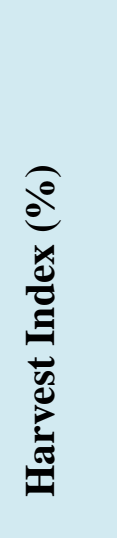 & 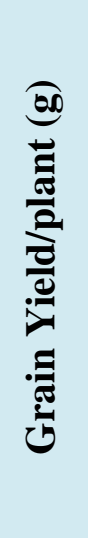 \\
\hline Cluster I & 64.1 & 72.12 & 99.1 & 25.6 & 2.06 & 2.92 & 6.67 & 7.86 & 4.01 & 14.9 & 1.38 & 21.19 & 1.27 & 1.48 & 37.59 & 0.96 \\
\hline Cluster II & 55.94 & 63.55 & 90.55 & 25.19 & 1.98 & 2.39 & 5.85 & 7.45 & 3.86 & 13.63 & 1.35 & 18.14 & 1.19 & 1.49 & 38.22 & 0.93 \\
\hline Cluster III & 68.77 & 76.77 & 103.77 & 26.5 & 2.14 & 4.44 & 8.54 & 7.76 & 4.41 & 21.4 & 1.38 & 29.62 & 1.37 & 1.45 & 38.48 & 1.02 \\
\hline Cluster IV & 71.5 & 79.5 & 106.5 & 27.45 & 2.08 & 9.55 & 13.53 & 7.25 & 3.56 & 23.53 & 1.42 & 29.56 & 1.6 & 1.54 & 32.23 & 1.05 \\
\hline Cluster V & 62.67 & 70.67 & 97.67 & 22.23 & 2.28 & 5.41 & 10.21 & 6.83 & 4.19 & 19.03 & 1.39 & 24.59 & 1.37 & 1.29 & 37.07 & 0.99 \\
\hline Cluster VI & 61.67 & 69.67 & 96.67 & 26.94 & 1.91 & 2.47 & 5.61 & 6.61 & 2.33 & 11.35 & 1.49 & 20.06 & 1.06 & 1.37 & 40.16 & 0.88 \\
\hline Cluster VII & 58.83 & 66.83 & 94 & 27.04 & 1.88 & 4.3 & 7.36 & 8.86 & 6.9 & 29.22 & 1.38 & 44.28 & 1.47 & 1.44 & 38.58 & 1.11 \\
\hline Cluster VIII & 63.17 & 71.17 & 98.17 & 26.33 & 2.09 & 5.3 & 8.91 & 10.9 & 3.13 & 24.34 & 1.35 & 31.58 & 1.41 & 1.54 & 40.19 & 1.07 \\
\hline Cluster IX & 62 & 70 & 97 & 23.77 & 2.32 & 3.46 & 8.13 & 11.16 & 4 & 14.25 & 1.36 & 19.46 & 1.37 & 1.56 & 38.26 & 0.99 \\
\hline Cluster X & 61.83 & 69.83 & 96.83 & 26.54 & 1.87 & 2.93 & 5.95 & 6.07 & 2.97 & 15.06 & 1.33 & 18.31 & 1.53 & 1.57 & 30.93 & 1 \\
\hline Cluster XI & 64.5 & 65.39 & 92.39 & 22.15 & 1.92 & 3.64 & 6.9 & 8.66 & 3.65 & 14.25 & 1.24 & 15.58 & 1.22 & 1.5 & 33.37 & 0.91 \\
\hline Cluster XII & 67.67 & 75.67 & 102.67 & 24.88 & 2.32 & 3.31 & 8.2 & 9.07 & 3.64 & 17.52 & 1.34 & 22.46 & 1.51 & 1.38 & 28.67 & 0.95 \\
\hline Cluster XIII & 60.83 & 68.67 & 95.67 & 21.7 & 2.11 & 4.17 & 8.15 & 5.71 & 3.36 & 30.29 & 1.32 & 38.03 & 1.44 & 1.49 & 41.6 & 1.11 \\
\hline Cluster XIV & 64.17 & 66.92 & 93.92 & 27.29 & 2.37 & 9.81 & 14.96 & 8.29 & 7.74 & 43.71 & 1.3 & 47.86 & 1.7 & 1.42 & 36.86 & 1.15 \\
\hline Cluster XV & 64.17 & 73.17 & 99.33 & 27.83 & 2.44 & 3.62 & 9.09 & 8.76 & 3.66 & 32.43 & 1.28 & 35.46 & 1.72 & 1.49 & 33.96 & 1.13 \\
\hline
\end{tabular}


Figure.1 Clustering by Tocher Method

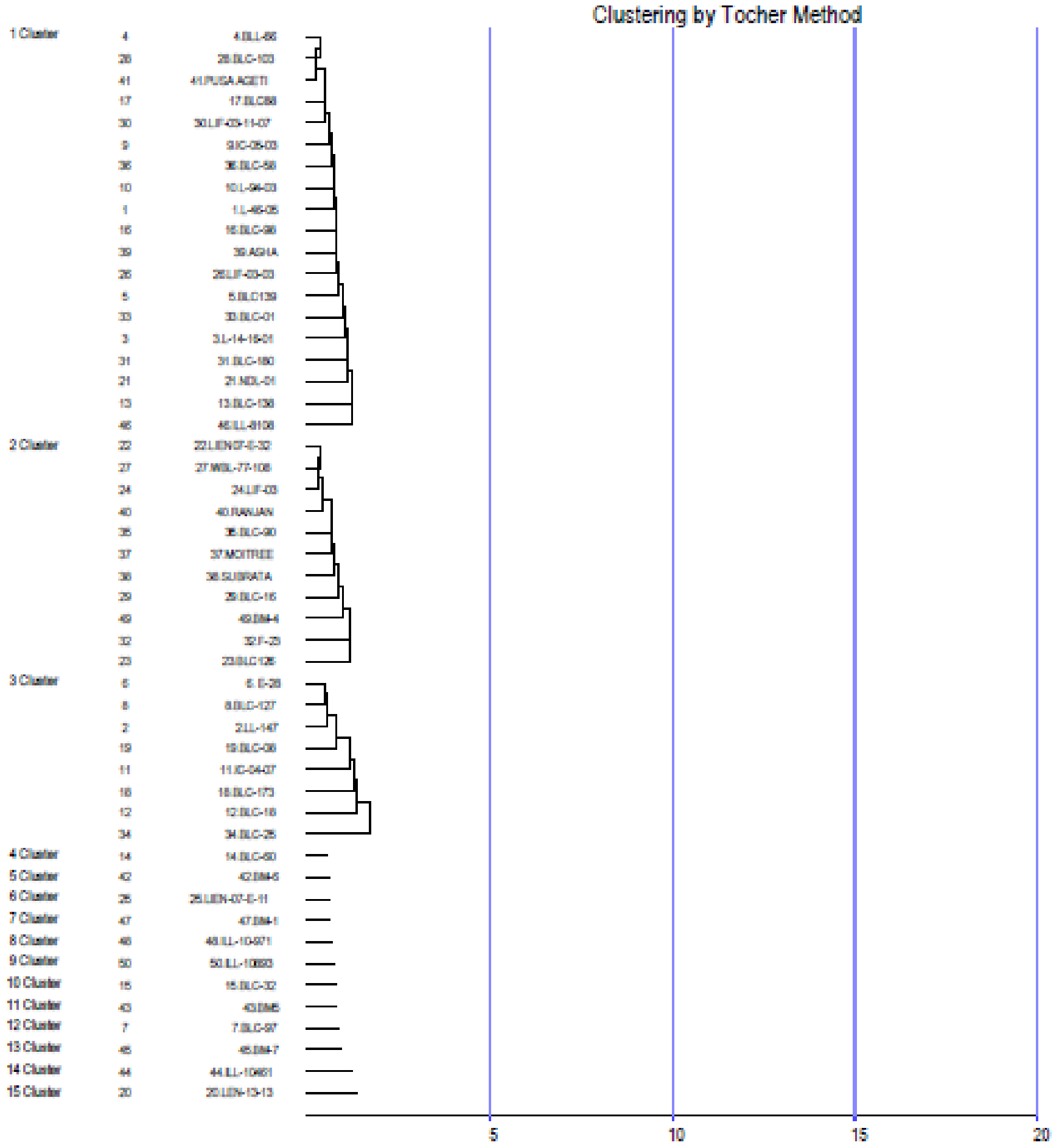


The highest mean value was found for the character days to $50 \%$ pod maturity in cluster IV (106.5) while it was lowest in cluster II (90.55). For days to $50 \%$ flowering, cluster II had lowest mean value (55.94) and cluster IV had highest mean value (71.5). It was observed for the character days to pod initiation that cluster II exhibited minimum mean value (63.55) while, cluster IV had maximum mean value (79.5). For plant height, cluster XIII had lowest mean value (21.7) and cluster XV had highest (27.83). Primary branches had shown minimum mean values for genotype fallen in cluster $\mathrm{X}$ (1.87) and highest (2.44) in cluster XV. Cluster II had lowest mean (2.39) for secondary branches/plant and cluster XIV exhibited highest mean value (9.81) for this character. Total branches/ plant had shown a minimum mean (5.61) in cluster VI whereas, it was maximum (14.96) in cluster XIV. Root length had lowest mean value (5.71) in cluster XIII and highest mean (11.16) in cluster IX. Cluster VI exhibited minimum mean (2.33) for nodules/plant while, cluster XIV exhibited the maximum mean (7.74). Pods/plant had shown minimum mean value (11.35) in cluster VI and maximum (43.71) in cluster XIV. Seeds/pod had minimum mean (1.24) in cluster XI and it was maximum (1.49) in cluster VI. The trait seeds/plant had lowest mean value (15.58) in cluster XI and highest (47.86) in cluster XIV. Biomass exhibited lowest mean value (1.06) in cluster VI while, it was highest (1.72) in cluster XV. Cluster V had minimum mean (1.29) and cluster $\mathrm{X}$ had maximum mean (1.57) for 100 seed weight. Harvest index exhibited minimum mean value (28.67) in cluster XII and maximum mean value (41.6) in cluster XIII. Lowest mean value was observed for grain yield in cluster VI (0.88) while it was highest in cluster XIV (1.15).It aided in deciding particular genotype from selected cluster. Cluster XIV having genotype ILL-10461 may be utilized in breeding programme as a parent.
From above results it may be concluded that the initiation of crossing programme by planned intermating of genetically divergent genotypes from cluster III with cluster II or Cluster XIV which had highest mean value for yield may lead to production of promising recombinants of lentil. These results followed the findings of Kumar et al., (2012) and Pandey and Bhatore (2018).

In conclusion, the various genotypes under study were grouped into fifteen different clusters with maximum inter cluster distances between cluster II and cluster IV with eleven genotypes and one genotype in each, respectively. Consequently, it was suggested that the crossing programme should be carried away between genotypes belonging to these clusters to obtain maximum heterosis. For advance research and crop improvement programmes, it is propounded to go for crossing programme between genetically divergent genotypes from cluster II and III to produce better recombinants for development of promising varieties in lentil. Cluster XIV having genotype ILL-10461 had shown maximum mean value for yield. Thus, it is recommended to take it as a parent and find superior cross combinations between genotypes belonging to cluster III to get elite progeny from the cross.

\section{Acknowledgement}

The authors acknowledge Mr. A.K.Manna, scientist, PORS, West Bengal for providing germplasm for conductance of this research work. Sincere acknowledgement is also there for IFAD-ICARDA project in SOUTH ASIA on "Enhancing food and nutritional security and improved livelihoods through intensification of rice-fallow system with pulse crops" running at Visva-Bharati centre for providing support to carry out the experiment. 


\section{References}

Anderson, E., A semigraphical method for the analysis of complex problems. Proceedings National Academy of Science, Washington, 1957, 43, 923927.

Anonymous, Google databases, www.google.com, 2018-19.

Arumuganathan, K. and Earle, E.D., Nuclear DNA content of some important plant species. Plant Mol. Biol. Report.9, 1991, 208-218.

Callaway, J. C. (2004). Hempseed as a nutritional resource: An overview. Euphytica, 140, 65-72.

Gautam, N.K., Singh, M., Khan, Z., Roy, A., Akhtar, J. and Ram, B. (2013). Assessment of lentil germplasm with respect to agronomic performance and major biotic stress. Legume Research, 36(3), 214-219.

Jeena, A.S. and Singh, I.S. (2002). Genetic divergence analysis in wild lentils. Legume Research, 25(3), 175-179.

Kumar, R., Sharma S.K., Malik, BPS. , Sharma, A., Sharma, R. (2004). Genetic diversity in lentil (Lens culnaris Medik). Legume Research, 27(2),111114.

Kumar, J., Basu, P. S., Srivastava, E., Chaturvedi, S. K., Nadarajan, N., \& Kumar, S. (2012). Phenotyping of traits imparting drought tolerance in lentil. Crop and Pasture Science, 63(6), 547-554.
Mahalanobis, P.C. (1936). On the generalized distance in statistics. Proceedings of National Institute of Science India, 2, 49-55.

Malik, R. (2005). Genetic divergence analysis in lentil (Lens culnaris Medik). M.Sc. Thesis, Department of Agricultural Botany, Ch. Charan Singh University, Meerut (U.P.), India.

Pandey, S. and Bhatore, A. (2018). Genetic diversity analysis for quantitative traits in indigenous germplasm of lentil in Madhya Pradesh. Journal of Pharmacognosy and Phytochemistry, 7(1), 279-283.

Sihag, R., Hooda, J.S., Vashishtha, R.D. and Malik, R.P.S. (2004). Genetic divergence in soybean [Glycine max (L.) Merrill]. Annals Biol., 20(1),17-21.

Sirohi, SPS. and Dar, A.N. (2009). Genetic divergence in soybean (Glycine max L. Merrill). SKUAST Journal of Research. 11(2),200-203.

Sirohi, S. P. S., Ramashray, Y. and Meenakshi, S. (2007). Assaying genetic divergence for morpho-physiological traits in lentil (Lens culinaris Medik.). Plant Archives, 7(1), 331-333.

Subhashchandra, B., Lohithaswa, H.C., Desai, S.A., Hanchinal, R.R., Kalappanavar, I.K., Math, K.K et al., (2009). Assessment of genetic variability and relationship between genetic diversity and transgressive segregation in tetraploid wheat. Karnataka Journal of Agricultural Science, 22(1), 36- 38.

\section{How to cite this article:}

Soumya Satpathy and Sandip Debnath. 2020. Assessment of Genetic Divergence for Quantitative Traits in Lens culinaris Medik. Int.J.Curr.Microbiol.App.Sci. 9(02): 252-261. doi: https://doi.org/10.20546/ijcmas.2020.902.032 